\title{
Prevalence and Predictors of Health-Related Internet and Digital Device Use in a Sample of South Asian Adults in Edmonton, Alberta, Canada: Results From a 2014 Community-Based Survey
}

Mark J Makowsky ${ }^{1}$, BSP, PharmD; Charlotte A Jones ${ }^{2}$, FRCP(C), PhD, MD; Shahnaz Davachi ${ }^{3}$, RNutr, RD, PhD

${ }^{1}$ Faculty of Pharmacy and Pharmaceutical Sciences, University of Alberta, Edmonton, AB, Canada

${ }^{2}$ Faculty of Medicine, Southern Medical Program, University of British Columbia Okanagan Campus, Kelowna, BC, Canada

${ }^{3}$ Primary Health Care, Alberta Health Services, Calgary, AB, Canada

Corresponding Author:

Mark J Makowsky, BSP, PharmD

Faculty of Pharmacy and Pharmaceutical Sciences

University of Alberta

2-142E Katz Group - Rexall Centre for Pharmacy \& Health Research

1136187 Avenue

Edmonton, AB, T6G 2E1

Canada

Phone: 17804921735

Fax: 17804921217

Email: makowsky@ualberta.ca

\section{Abstract}

Background: South Asian Canadians are at high risk of developing cardiovascular disease and diabetes. Consumer-oriented health information technology may help mitigate lifestyle risk factors and improve chronic disease self-management.

Objective: This study aims to explore the prevalence, patterns, and predictors of the use of the internet, digital devices, and apps for health purposes as well as preferences for future use of eHealth support in South Asian Canadians.

Methods: We conducted a cross-sectional, mixed-mode survey in a convenience sample of 831 South Asian adults recruited at faith-based gathering places, health care settings, and community events in Edmonton, Alberta, in 2014. The 706 responders (mean age 47.1, SD 17.6 years; $\mathrm{n}=356,50.4 \%$ female; $\mathrm{n}=509,72.1 \% \mathrm{Sikh}$ ) who provided complete sociodemographic information were included in the analysis, and the denominators varied based on the completeness of responses to each question. Multivariate logistic regression was used to determine sociodemographic and health status predictors of internet use, being a web-based health information seeker, smartphone or tablet ownership, health app use, and willingness to use various modes of eHealth support.

Results: Of all respondents, 74.6\% (527/706) were internet users and 47.8\% (336/703) were web-based health information seekers. In addition, 74.9\% (527/704) of respondents owned a smartphone or tablet and 30.7\% (159/518) of these had a health and fitness app. Most internet users (441/527, 83.7\%) expressed interest in using $\geq 1$ mode of eHealth support. Older age, being female, having less than high school education, preferring written health information in languages other than English, and lacking confidence in completing medical forms predicted lack of internet use. Among internet users, factors that predicted web-based health information seeking were being female, use of the internet several times per day, being confident in completing medical forms, and preferring health information in English. Predictors of not owning a smartphone or tablet were being older, preferring health information in languages other than English, having less than high school education, living in Canada for $<5$ years, having a chronic health condition, and having diabetes. Increasing age was associated with lower odds of having a health app. Preferring health information in languages other than English consistently predicted lower interest in all modes of eHealth support.

Conclusions: eHealth-based chronic disease prevention and management interventions are feasible for South Asian adults, but digital divides exist according to language preference, education, age, sex, confidence in completing medical forms, and number of years lived in Canada. Community-based, culturally tailored strategies targeting these factors are required to address existing divides and increase the uptake of credible web-based and app-based resources for health purposes.

(JMIR Public Health Surveill 2021;7(1):e20671) doi: 10.2196/20671 


\section{KEYWORDS}

consumer health information; cardiovascular disease; type 2 diabetes; eHealth; mobile phone; ethnicity; cross-sectional survey; Canada

\section{Introduction}

South Asians originating from India, Pakistan, Bangladesh, and Sri Lanka are among the fastest growing and largest visible minority groups in Canada [1]. Cardiovascular disease (CVD) and diabetes are among the most prevalent health problems facing South Asians regardless of whether they live in their country of origin or abroad [2]. Recent reviews have highlighted that South Asian migrants in Canada have 1.5 to 2 times the prevalence of coronary artery disease compared with age- and sex-adjusted Whites of European ancestry [2-4]. New cases of CVD disproportionally affect younger South Asian individuals. This was demonstrated in a large, international case-control study where the median age of first myocardial infarction in South Asians (53 years) was 6 to 10 years younger than those in North America or Western Europe [5].

The increased risk of coronary artery disease is primarily driven by a higher incidence of known atherosclerotic CVD risk factors, particularly type 2 diabetes and impaired glucose tolerance [6]. Both biological and nonbiological mechanisms are implicated in the increased risk of coronary artery disease and diabetes. For example, a recent meta-analysis found that South Asian Canadians had a higher prevalence of type 2 diabetes, hypertension, abdominal obesity, percentage body fat, increased carbohydrate intake, and sedentary lifestyle [3]. Individual studies have shown that South Asians are 2 to 3 times more likely to develop type 2 diabetes compared with other populations and develop diabetes at a younger age; approximately 4.6 years younger than Chinese or White Canadians [7-10]. Differences in genetic factors may explain some of the increased rates of CVD risk factors, but existing evidence suggests that the biology of CVD is no different in South Asians compared with other ethnic groups [6]. Nonbiologic mechanisms, including acculturation, a shift from traditional dietary habits, physical inactivity, other environmental factors (eg, psychosocial stress, social support), and access to health services, have all been implicated in the increased risk of CVD, diabetes, and other CVD-related risk factors $[6,11,12]$.

Clinical practice guidelines recommend lifestyle management focusing on diet and physical activity, pharmacologic therapy, and self-management education in the primary prevention and management of CVD and diabetes and their associated risk factors $[6,13,14]$. Despite these recommendations, evidence suggests that risk factors and diabetes control are suboptimal in South Asian individuals [15]. Canadian data suggest that $55 \%$ of South Asian patients are above-recommended blood glucose $\mathrm{A}_{1 \mathrm{c}}$ targets, $36 \%$ exceed blood pressure targets, and $58 \%$ exceed lipid level targets [15]. Language barriers, sociocultural factors, limited diabetes and CVD awareness, lack of access to culturally tailored diet counseling, misconceptions around diet, perceptions around physical activity, and lower compliance with pharmacotherapy may contribute to the increased risk [2,16-18].

There has been large growth in consumer-oriented health information technology, such as Web 2.0, and app-based interventions supporting healthy lifestyles and the management of chronic health conditions [19]. Emerging evidence suggests that mobile health (mHealth), internet, and social media-based interventions may improve the prevention and management of chronic health conditions [20], cardiovascular risk factors including unhealthy diet and physical inactivity [21,22], and diabetes [23-25]. Several successful culturally tailored programs targeting diabetes and cardiovascular risk have been developed in Canada, but accessing these programs can be challenging [26-30]. The use of credible consumer-oriented eHealth resources by the South Asian community in Canada could increase access to and efficiency in the delivery of culturally tailored chronic disease self-management programs, which may further assist in the prevention and management of CVD and type 2 diabetes and their common risk factors and complications in this high-risk population.

Large, nationally representative surveys suggest high levels of digital device ownership [31], uptake of the internet [32], and web-based health information seeking in North America $[33,34]$. However, digital divides in internet use for health information related to sociodemographic factors and ethnicity [35] exist in the United States. There is limited information on use patterns and predictors of web-based health information-seeking behaviors and use of digital devices for health purposes among English- and Punjabi-speaking South Asian Canadians. This information is important and could be used to justify and inform the development of tailored consumer-oriented eHealth interventions. Such interventions may help to overcome identified gaps in the knowledge and skills needed to effectively apply high-quality web-based and mobile phone-based resources for the prevention and management of chronic conditions. This information could also be used to inform and assist clinicians on how to optimally engage individuals with existing web-based health information resources.

The objective of this study is to describe prevalence, patterns, and predictors of internet use for health purposes, ownership of digital devices, use of health and fitness apps, and preferences for different eHealth-based support tools in a sample of Englishor Punjabi-speaking South Asian adults recruited from Edmonton, Alberta. Specifically, we explore the extent to which these variables are influenced by sociodemographic, health status, and technology use factors, including age, gender, education, health literacy, language preferences, and the presence of chronic health conditions. 


\section{Methods}

\section{Study Design}

We used a community-based approach and worked in partnership with 13 faith-based, cultural, community, and health care organizations in a major metropolitan Canadian city, Edmonton, Alberta. We conducted a descriptive cross-sectional, mixed-mode anonymous survey. The survey was primarily delivered via a computer-assisted personal interview using the Qualtrics (Qualtrics Corporation) web-based survey platform. One-on-one interviews using paper-based surveys and an optional web-based version were also used.

\section{Participants, Recruitment, and Survey Administration}

Participant recruitment occurred at 4 gurdwaras, 2 temples, 1 community pharmacy, 1 medical clinic, 2 community centers, and 2 large South Asian community events between May 18 and August 31, 2014. English- or Punjabi-speaking community members were eligible to participate if they were aged older than 18 years, self-identified their ethnic origins in India, Pakistan, Bangladesh, Nepal, or Sri Lanka, and were currently living in Alberta.

At community events, potential respondents were notified of the presence of the research team via announcements and posters. Potential respondents were then approached by community volunteers and presented with the survey information letter and asked if they would like to participate. If the potential participant agreed to participate, consent was implied and the survey was administered. Bilingual, trained community volunteers administered the survey in English or Punjabi according to respondents' preference. Participants who felt comfortable using tablet computers self-administered the survey.

Potential participants who were unwilling to complete the in-person survey were invited to complete the survey on the web, which was also advertised using posters in the community, via social media and word of mouth. At selected survey locations, including the participating community pharmacy and family physician clinic, we attempted to recruit consecutive attendees. At these locations, the survey was conducted while waiting to have prescriptions filled or awaiting assessment. Respondents who completed the survey in person were offered a reusable shopping bag as an incentive and the opportunity to enter a draw for a tablet computer or various gift cards, whereas those who completed the survey on the web were only eligible to enter the draw.

\section{Survey Instrument}

The e-Patient Project Survey evaluated the levels of digital device ownership, internet use, health information-seeking behaviors, health and fitness app use, levels of eHealth literacy, and preferences for participation in different modes of eHealth support (Multimedia Appendix 1). The research team developed the survey in 3 stages: literature review, key informant interviews with 16 individuals from the target communities, and a pilot test with 19 other individuals from the target communities. Most of the items were adopted from existing instruments, including the Pew Research Centre's Internet \& American Life Project 2012 Health survey [34,36,37], the 2012
Statistics Canada Canadian Internet Use Survey [33], the eHealth Literacy Scale [38], and a health literacy screening questionnaire [39].

The survey was translated into Punjabi according to the World Health Organization guidance for translation and adaptation of instruments [40]. One translator with a medical background who was fluent in both Punjabi and English conducted forward translation from English to Punjabi. Emphasis was placed on conceptual rather than literal translations. A panel of 2 bilingual community member reviewers further identified and reviewed inadequate expressions and concepts in the translated version. The back translation was conducted by a separate translator who was fluent in both English and Punjabi. Translation discrepancies were discussed and addressed by the project team.

\section{Measurement of Outcome Variables}

We reported technology use outcomes as dichotomous variables. Individuals who answered affirmatively to either "Do you go online at least occasionally?" or "Do you send or receive email at least occasionally?" were characterized as internet users. Web-based health information seekers were those who indicated getting information about health on the internet or on the web. Individuals who answered affirmatively to "Is your cellphone a smartphone such as an iPhone, Android, Blackberry or Windows phone?" or "Do you own an iPad or other tablet computer such as an Android tablet, Microsoft surface or Kindle Fire?" were considered owners of a smartphone or tablet device. Owners of digital devices were asked about the use of health and fitness apps using one question, "On your smartphone or tablet, do you happen to have any health or fitness software apps (eg, track your food intake, weight, physical activity, or keep track of your medications)." We explored internet users' preferences for the use of 6 different modes of eHealth support in the future, including (1) accessing a webpage includes a forum where you could connect with others like you, (2) accessing a YouTube channel for people with your condition(s) that has experts talking about best management, (3) using a smartphone app or wearable device that can monitor your condition, track your progress on your health goals, and/or provide reminders about when to take your medications, (4) following a specific Twitter account for your condition(s), (5) signing up for personalized text messages providing health updates or reminders for your condition(s), or (6) using a web-based education program. We adjusted the response options to those who indicated having at least one chronic condition, those who indicated they had diabetes, or those without a chronic condition.

\section{Measurement of Sociodemographic and Health Status Predictor Variables}

Demographic factors included age, sex, education, marital status, duration of time lived in Canada, and the South Asian community with which respondents identified. Self-rated health status was assessed using a single question from the 36-item Short Form survey. The presence of 6 chronic health conditions was assessed by asking, "Have you ever been told by a doctor, nurse or other health care professional that you have, followed by the response options (eg, 'diabetes or sugar disease')." Language preference was assessed by asking, "In what language would you prefer to receive written health information?" and 
categories were collapsed into includes English or does not include English. One question "How confident are you filling out medical forms by yourself" estimated health literacy [39].

\section{Analysis}

We limited the analysis to individuals who provided complete information on sociodemographic variables, language preference, health literacy, health status, and diabetes status variables. Surveys with missing data for other items were included in the analysis. Descriptive statistics were tabulated and depicted as the proportion of valid cases where incomplete responses for each outcome variable and choose to not answer or don't know responses were considered missing. Descriptive data were analyzed using SPSS version 23 for Mac (IBM Corporation). Logistic regression was performed using R 3.1.3 (The R Foundation) to assess the effect of demographic and health factors on the dichotomous outcome variables. Variables shown to be statistically $(P<.05)$ and clinically significant in the descriptive and univariate level analyses were selected to be included in the models. Self-rated health status was dropped for models that could not include all the factors. This was based on the widely used rule of thumb that there should be at least 10 events per parameter. This factor was dropped, as it was thought to be the least important. Other models included all variables. Multicollinearity was assessed by variance inflation factor (VIF), and VIF coefficients $>10$ were considered as high multicollinearity.

Goodness-of-fit, measuring the discrepancy between observed values and the expected value under the model, was assessed by using Craig and Uhler Pseudo R-square, Hosmer and Lemeshow goodness-of-fit test, and area under the curve (AUC). A $P$ value $<.05$ indicated statistical significance. All the models fit reasonably well, as multicollinearity was not present in any model, all $P$ values for the Hosmer-Lemeshow goodness-of-fit were $>.05$ (indicating no evidence of poor fit), and all AUC scores were greater than 0.7. However, most Craig and Uhler Pseudo R-square values were low $(<0.5)$.

\section{Ethics Approval}

The Health Research Ethics Board at the University of Alberta (Pro00038210) approved this study.

\section{Results}

\section{Participant Flow}

We approached 1126 potential participants for face-to-face surveys at community events and 831 agreed to complete the survey. A total of 706 individuals $(706 / 831,85.0 \%)$ provided complete sociodemographic and health status information (Figure 1).

Figure 1. Flow diagram of the e-Patient Project Survey, Edmonton, Alberta, in 2014.

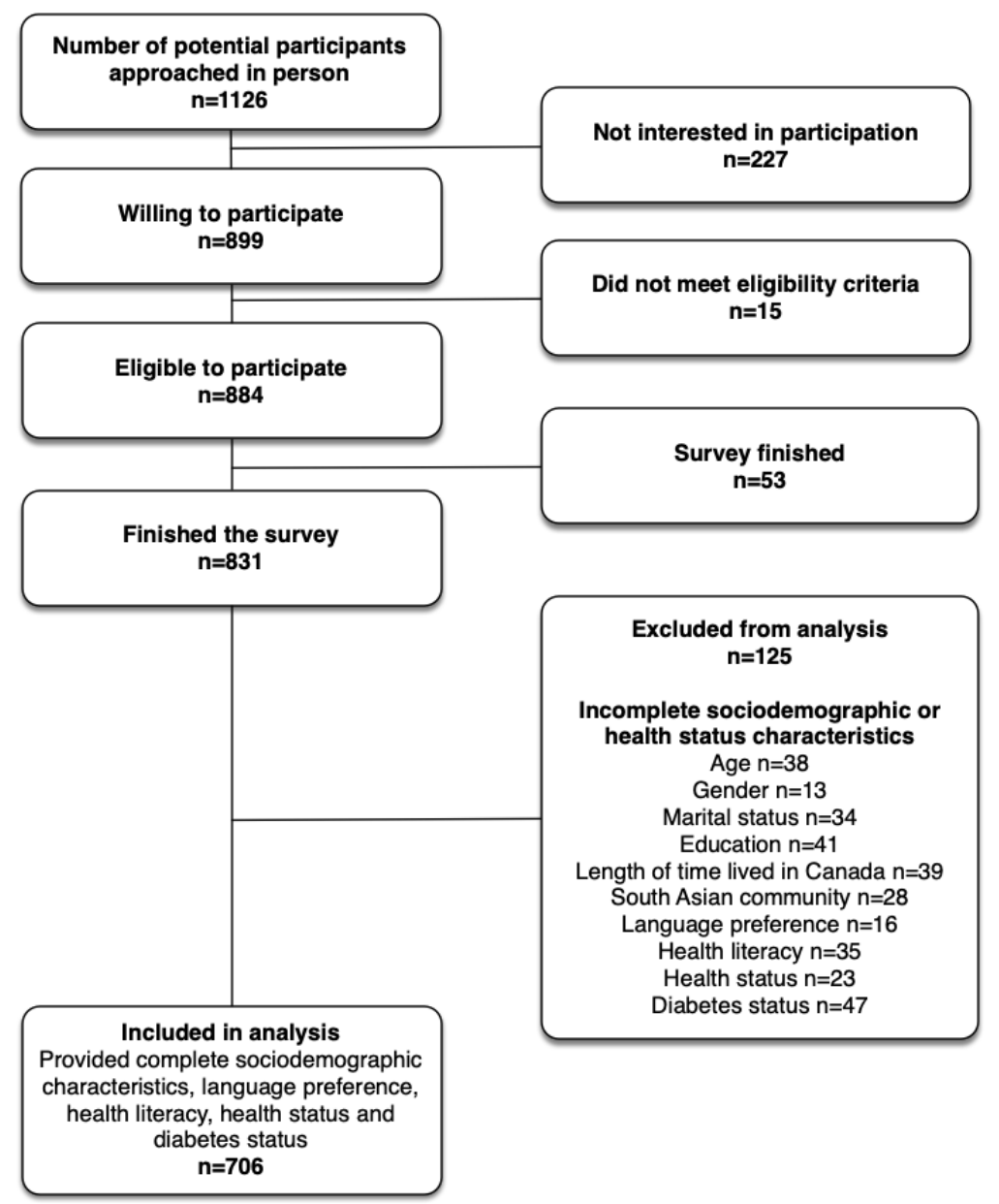




\section{Participant Characteristics}

The characteristics of the 706 study participants are shown in Table 1. Overall, the mean age was 47.1 (SD 17.6) years, and $50.4 \%$ (356/706) were female, 64.6\% (456/706) had college or university education, and $72.1 \%$ (509/706) self-identified as Sikh. A total of $25.4 \%$ (179/706) of the participants lived in Canada for $<5$ years, and 31.0\% (219/706) preferred written health information in a language other than English. Overall, $53.4 \%(377 / 706)$ of the participants self-reported at least one chronic health condition and 19.8\% (140/706) reported diabetes. Most respondents rated their own health in the past 4 weeks as $\operatorname{good}(283 / 706,40.1 \%)$ or very $\operatorname{good}(169 / 706,23.9 \%)$, whereas $15.6 \%(110 / 706)$ and $3.7 \%(26 / 706)$ rated their health status as fair and poor, respectively. In addition, 11\% (78/706) of the participants indicated being not at all confident in filling out medical forms on their own. Most respondents (397/706, 56.2\%) were recruited at places of faith-based gathering and community events, whereas a minority $(41 / 706,5.8 \%)$ completed the survey on their own on the web. 
Table 1. Demographic characteristics of the study sample.

\begin{tabular}{|c|c|c|}
\hline Characteristics & Respondents & Missing data, $\mathrm{n}(\%)$ \\
\hline Age (years;n=706) & & $\mathrm{N} / \mathrm{A}^{\mathrm{a}}$ \\
\hline Mean (SD) & $47.1(17.6)$ & \\
\hline Median (IQR) & $45(32-63)$ & \\
\hline Age group (years; $n=706), n(\%)$ & & N/A \\
\hline $18-34$ & $213(30.2)$ & \\
\hline $35-49$ & $181(25.6)$ & \\
\hline $50-64$ & $156(22.1)$ & \\
\hline$\geq 65$ & $156(22.1)$ & \\
\hline $\operatorname{Sex}(n=706), n(\%)$ & & N/A \\
\hline Male & $350(49.6)$ & \\
\hline Female & $356(50.4)$ & \\
\hline Marital status $(\mathrm{n}=706), \mathrm{n}(\%)$ & & N/A \\
\hline Not married & $140(19.8)$ & \\
\hline Married & $566(80.2)$ & \\
\hline Education $(\mathrm{n}=706), \mathrm{n}(\%)$ & & N/A \\
\hline Less than high school & $63(8.9)$ & \\
\hline High school & $187(26.3)$ & \\
\hline College, university, or higher & $456(64.6)$ & \\
\hline Lived in Canada (years; $n=706), n(\%)$ & & N/A \\
\hline$>5$ & $527(72.1)$ & \\
\hline $0-5$ & $179(25.4)$ & \\
\hline Community $(\mathrm{n}=706), \mathrm{n}(\%)$ & & N/A \\
\hline Sikh & $509(72.1)$ & \\
\hline Hindu & $134(19.0)$ & \\
\hline Other & $63(8.9)$ & \\
\hline Language preference $(n=706), n(\%)$ & & N/A \\
\hline English & $487(69.0)$ & \\
\hline Not English & $219(31.0)$ & \\
\hline Confidence in filling out medical forms $(n=706), n(\%)$ & & N/A \\
\hline Greater than not at all & $628(89.0)$ & \\
\hline Not at all & $78(11.0)$ & \\
\hline Health status $(n=706), n(\%)$ & & N/A \\
\hline Excellent & $118(16.7)$ & \\
\hline Very good & $169(23.9)$ & \\
\hline Good & $283(40.1)$ & \\
\hline Fair & $110(15.6)$ & \\
\hline Poor & $26(3.7)$ & \\
\hline \multicolumn{3}{|l|}{ Medical conditions, $\mathbf{n}(\%)^{b}$} \\
\hline Diabetes or sugar disease $(n=706)$ & $140(19.8)$ & N/A \\
\hline High blood pressure $(n=706)$ & $178(25.2)$ & N/A \\
\hline Heart disease (eg, angina, heart attack, or stroke; $n=689$ ) & $48(7.1)$ & $17(2.4)$ \\
\hline
\end{tabular}




\begin{tabular}{|c|c|c|}
\hline Characteristics & Respondents & Missing data, $\mathrm{n}(\%)$ \\
\hline Lung conditions (eg, asthma or bronchitis; $\mathrm{n}=687$ ) & $41(5.8)$ & $19(2.7)$ \\
\hline Arthritis $(\mathrm{n}=688)$ & $124(17.6)$ & $18(2.5)$ \\
\hline Cancer $(n=684)$ & $23(3.4)$ & $22(3.1)$ \\
\hline Other chronic condition treated with daily medication $(n=688)$ & $110(16.2)$ & $18(2.5)$ \\
\hline High cholesterol $(n=608)^{\mathrm{c}}$ & $144(23.7)$ & $98(13.9)$ \\
\hline$\geq 1$ condition $(n=706), n(\%)$ & & N/A \\
\hline No & $329(46.6)$ & \\
\hline Yes & $377(53.4)$ & \\
\hline Location of recruitment $(n=706), n(\%)$ & & N/A \\
\hline Community setting & $397(56.2)$ & \\
\hline Health setting & $268(38.0)$ & \\
\hline On the web & $41(5.8)$ & \\
\hline
\end{tabular}

${ }^{\mathrm{a}} \mathrm{N} / \mathrm{A}$ : not applicable.

${ }^{\mathrm{b}}$ Data are $\mathrm{n}(\%)$ out of 706 respondents unless there were missing data, in which case the $\mathrm{n}(\%)$ of valid cases is reported.

${ }^{\mathrm{c}}$ High cholesterol was unintentionally omitted from the paper version of the survey administered at the first community event.

\section{Internet Use, Sources of Health Information, and Web-Based Health Information-Seeking Behavior in Internet Users}

Overall, 74.6\% (527/706) of respondents were classified as internet users, whereas $25.4 \%$ (179/706) were nonusers (Table 2). Respondents used a median of 3 (IQR 2-5) different sources of health information, most commonly their doctor or health care provider $(656 / 704,93.2 \%)$ and family $(398 / 702,56.7 \%)$. Overall, $47.8 \%$ (336/703) of all respondents, or $63.4 \%$ (332/524) of internet users, used the internet for health information (Table 2). When asked how important it is to find health information tailored to their specific needs as a person of a South Asian background, $73.8 \%$ (513/695) indicated it was very or extremely important.

Patterns of use among the 527 internet users are shown in Multimedia Appendix 2. Most internet users (373/517, 72\%) were on the web several times per day and most watched videos on YouTube, used social media sites, or made video calls. The most commonly reported web-based health information-seeking tasks were looking for information on healthy lifestyles $(354 / 524,67.6 \%)$ and on a specific disease or medical condition $(248 / 460,53.9 \%)$ and symptoms they were experiencing $(222 / 523,42.4 \%)$.

Regarding the use of Web 2.0 for health, just less than half of internet users $(240 / 523,45.9 \%)$ watched a web-based video about health or medical issues, $42.4 \%$ (222/523) read about someone else's experience about health or medical issues in a blog, newsgroup, or website, and 29.5\% (153/518) reported going on the web to find others who might have similar health concerns. Although there were significant missing data because of a problem with the printed version of the survey, just more than one-fourth of respondents indicated that web-based health information they found or someone else found for them affected a treatment decision $(94 / 343,27.4 \%)$, whereas more participants responded that it had led them to ask their doctor new questions, go to see their doctor, or change the way they maintain their health (Multimedia Appendix 2). 
Table 2. Internet user status, sources of health information, digital device ownership, and health and fitness apps.

\begin{tabular}{llc}
\hline Characteristics & Overall, $\mathrm{n}(\%)$ & Missing data, $\mathrm{n}(\%)$ \\
\hline Internet use $(\mathbf{n}=\mathbf{7 0 6})$ & $527(74.6)$ & $\mathrm{N} / \mathrm{A}^{\mathrm{a}}$ \\
$\quad$ Internet user & $179(25.4)$ & $\mathrm{N} / \mathrm{A}$ \\
$\quad$ Noninternet user & & $2(0.3)$ \\
Where do you get information about health questions that you have? & $656(93.2)$ & $4(0.6)$ \\
Doctor or health care provider $(\mathrm{n}=704)^{\mathrm{b}}$ & $398(56.7)$ & $3(0.4)$ \\
Family $(\mathrm{n}=702)$ & $336(47.8)$ & $2(0.3)$ \\
Internet $(\mathrm{n}=703)$ & $309(43.9)$ & $3(0.4)$ \\
Print $(\mathrm{n}=704)$ & $285(40.5)$ & $2(0.3)$ \\
Friends $(\mathrm{n}=703)$ & $283(40.1)$ & $67(9.5)$ \\
TV or radio $(\mathrm{n}=705)$ & $66(10.3)$ & $88(12.5)$
\end{tabular}

How important is it for you to find health information tailored to your needs as someone of South Asian background? (n=695)

Extremely or very important

Device ownership (Do you own...)

A desktop or laptop computer at home connected to the internet? $(n=701)$

A cellphone, iPhone, Blackberry, or other device that is a cellphone? $(n=706)$

Is your cellphone a smartphone? $(\mathrm{n}=571)$

An iPad or other tablet computer $(\mathrm{n}=704)$

Smartphone or tablet $(n=704)$

Device use (Do you use your smartphone or tablet to...)

Send or receive text messages $(n=527)$

On your smartphone or tablet, do you happen to have any health or fitness apps? $(n=518)$

What type of health and fitness apps are you currently using? $(n=138)$

Tracking food, diet, or calorie intake

Monitoring weight

Physical activity tracking

Track runs that you take

Mobile pedometer

Research or diagnose medical conditions

Keep track of medications

Stress management

Communicate with your doctor or health care provider

Monitor sleep cycle

Record your blood pressure

Record your blood sugar or diabetes

Other
513 (73.8)

$11(1.6)$

615 (87.7)

$5(0.7)$

571 (80.9)

N/A

443 (77.6)

N/A

376 (53.4)

$2(0.3)$

527 (74.9)

$2(0.3)$

432 (82.0)

N/A

159 (30.7)

$9(1.7)$

88 (63.8)

21 (13.2)

49 (35.5)

21 (13.2)

65 (47.1)

21 (13.2)

20 (14.5)

21 (13.2)

32 (23.2)

21 (13.2)

9 (6.5)

21 (13.2)

$9(6.5)$

21 (13.2)

17 (12.3)

21 (13.2)

10 (7.2)

21 (13.2)

12 (8.7)

21 (13.2)

13 (9.4)

21 (13.2)

8 (5.8)

21 (13.2)

$6(4.3)$

aN/A: not applicable.

${ }^{\mathrm{b}}$ Data are $\mathrm{n}(\%)$ out of 706 respondents unless otherwise specified. When there were missing data, the $\mathrm{n}(\%)$ of valid cases was reported. 
Digital Device Ownership and Health and Fitness Apps in Smartphone or Tablet Owners

Overall, 62.8\% (443/705) of respondents owned a smartphone, $53.4 \%$ (376/704) owned a tablet computer, and 74.9\% (527/704) owned either a smartphone or tablet (Table 2). Most smartphone or tablet owners $(432 / 527,82 \%)$ reported sending or receiving text messages. Just less than one-third of the smartphone or tablet owners surveyed $(159 / 518,30.7 \%)$ indicated that they had a health and fitness app on their mobile device (Table 2). The most commonly used apps included those designed to track food, diet, or calorie intake $(88 / 138,63.8 \%)$, track physical activity $(65 / 138,47.1 \%)$, and monitor weight $(49 / 138,35.5 \%)$.

\section{Preferences for Future eHealth Interventions in Internet Users}

Most internet users $(441 / 527,83.7 \%)$ responded that they were likely or very likely to use at least one of the 6 presented eHealth tools to address a health issue in the next 12 months (Multimedia
Appendix 2). Although there were some systematic issues with missing information regarding YouTube, Twitter, and a web-based education program, most respondents favored accessing a YouTube channel $(330 / 425,77.6 \%)$ followed by using a webpage with peer-to-peer support (353/500, 70.6\%), using an app or a wearable device $(316 / 493,64.1 \%)$, or receiving personalized text messages $(282 / 483,58.4 \%)$.

\section{Barriers in Nonusers of the Internet}

The 179 respondents who were not internet users reported several barriers, the most common being lack of skills (114/177, 64.4) and no interest (72/177, 40.7\%; Table 3). One-third of nonusers $(57 / 178,32 \%)$ said they were planning to get on the web in the future. Of these, $67.3 \%$ (35/52) indicated being likely or very likely to attend a hands-on workshop, whereas $72.2 \%$ (38/52) were likely or very likely to learn from a friend or family member. Most internet nonusers (136/175, 77.7\%) reported knowing someone who could help them get on the web.

Table 3. Barriers to nonusers of the internet.

\begin{tabular}{|c|c|c|}
\hline Characteristics & Noninternet users, n (\%) & Missing data, $\mathrm{n}(\%)$ \\
\hline \multicolumn{3}{|l|}{ What are the reasons you do not go on web? ${ }^{\mathrm{a}}$} \\
\hline Lack of skills $(\mathrm{n}=177)$ & $114(64.4)$ & $2(1.1)$ \\
\hline No interest ( $\mathrm{n}=177)$ & $72(40.7)$ & $2(1.1)$ \\
\hline Too late to learn $(n=176)$ & $38(21.1)$ & $3(1.7)$ \\
\hline Limited access to a computer $(\mathrm{n}=176)$ & $9(5.1)$ & $3(1.7)$ \\
\hline Uncomfortable using a computer $(n=175)$ & $7(4.0)$ & $4(2.2)$ \\
\hline Privacy reasons $(n=176)$ & $7(4.0)$ & $3(1.7)$ \\
\hline Fear of technology $(n=175)$ & $5(2.9)$ & $4(2.2)$ \\
\hline Because of disability $(n=176)$ & $4(2.3)$ & $3(1.7)$ \\
\hline Cost $(n=178)$ & $3(1.7)$ & $1(0.6)$ \\
\hline \multicolumn{3}{|l|}{ Are you likely to start going on web in the future? } \\
\hline Yes, within 6 months $(\mathrm{n}=178)$ & $23(12.9)$ & $1(0.6)$ \\
\hline Yes, within 6 to 12 months $(\mathrm{n}=179)$ & $16(9.0)$ & $N / A^{b}$ \\
\hline Yes, in more than a year $(n=179)$ & $18(10.1)$ & N/A \\
\hline Not likely $(\mathrm{n}=179)$ & $61(34.3)$ & N/A \\
\hline Never $(n=179)$ & $60(33.7)$ & N/A \\
\hline \multicolumn{3}{|c|}{ Likeliness to use the following strategies to improve their ability to go on the web (n=57; who answered yes) } \\
\hline Likely or very likely to attend a hands-on workshop $(n=52)$ & $35(67.3)$ & $5(8.8)$ \\
\hline Likely or very likely to talk with a friend or family member $(n=52)$ & $38(72.2)$ & $5(8.8)$ \\
\hline Know someone who could help them, if they needed to go on web to do something ( $\mathrm{n}=175$ ) & $136(77.7)$ & $4(2.2)$ \\
\hline
\end{tabular}

${ }^{\mathrm{a}}$ Data are $\mathrm{n}(\%)$ out of 179 noninternet users unless otherwise specified. When there were missing data, the $\mathrm{n}(\%)$ of valid cases was reported.

${ }^{\mathrm{b}} \mathrm{N} / \mathrm{A}$ : not applicable.

\section{Predictors of Internet Use and Web-Based Health Information Seeking}

As shown in Multimedia Appendix 3, 5 of the predictor variables were associated with internet use in the multiple logistic regression analysis, including all 706 respondents. Preferring written information in a language other than English (odds ratio [OR] 0.21, 95\% CI 0.12-0.36), lacking confidence in filling out medical forms (OR $0.27,95 \%$ CI 0.11-0.65), being female (OR $0.47,95 \%$ CI $0.26-0.85$ ), and increasing age (OR 0.92, 95\% CI $0.90-0.94)$ were predictive of lower internet use, whereas educational achievement (OR 4.00, 95\% CI 1.52-11.07 for 
college university or higher) predicted greater odds of internet use.

There were 4 independent predictor variables of the use of the internet for health information in the 514 internet users. Females (OR 2.34, 95\% CI 1.49-3.71) and people who used the internet several times per day (OR 3.83, 95\% CI 2.36-6.30) were more likely to be web-based health information seekers, whereas those lacking confidence in filling out medical forms (OR 0.24, 95\% CI 0.07-0.72) and those expressing a preference for written health information in languages other than English (OR 0.53, 95\% CI 0.30-0.94) were less likely to be web-based health information seekers (Multimedia Appendix 3).

\section{Predictors of Digital Device Ownership and Having a Health and Fitness App}

A total of 6 predictor variables were associated with ownership of a smartphone or tablet when the whole group was assessed $(n=704)$ : educational achievement (college or university or higher: OR 5.44, 95\% CI 2.36-12.96) was associated with higher odds of device ownership, while living in Canada for $<5$ years (OR 0.47, 95\% CI 0.27-0.81), preferring written information in languages other than English (OR 0.51, 95\% CI 0.31-0.86), having a chronic health condition (OR $0.53,95 \%$ CI $0.31-0.90$ ), having diabetes (OR $0.50,95 \%$ CI $0.28-0.87$ ), and increasing age (OR 0.94, 95\% CI 0.92-0.95) were associated with lower odds of device ownership (Multimedia Appendix 3). In the subgroup of smartphone or tablet owners $(n=521)$, only increasing age was associated with lower odds of having downloaded a health and fitness app (OR 0.97, 95\% CI 0.95-0.99; Multimedia Appendix 3).

\section{Predictors of Preferences for Future eHealth Interventions in Internet Users}

The multivariable analysis shown in Multimedia Appendix 4 indicated that individuals who preferred written health information in a language other than English were less interested in all modes of eHealth-based support. Those who reported watching YouTube videos were more likely to be interested in a YouTube channel for health issues. Those who are married were more interested in a website with peer support. Interest in app-based interventions was higher in those who own a smartphone or tablet but lower in participants with diabetes. Interest in text message-based interventions was higher in older individuals, those who already send text messages, use the internet several times per day, or are married (Multimedia Appendix 4).

\section{Discussion}

\section{Principal Findings}

Among our sample of primarily Sikh South Asian adults recruited from community and health care settings, we found a high prevalence of internet users and ownership of smart digital devices that allow the use of apps. Health care providers were the most common source of health information, and only less than half of all respondents reported using the internet as a source of health information. Although most smartphone or tablet owners indicated that they used texting, only one-third reported having a health and fitness app on their device. The most commonly used apps were food, diet, or calorie intake trackers. Most internet users indicated that they were likely or very likely to use at least one of the eHealth tools to address a health issue in the next 12 months, and many preferred YouTube videos, a peer-to-peer support website, or smartphone app. Among internet nonusers, lack of technological skills and interest were cited as the most common barriers, and only one-third of these respondents indicated they were likely to get on the web in the future. However, just more than three-fourth of nonusers indicated that they had access to someone who could help them use the internet.

Language preferences, higher educational attainment, and age were common factors driving a digital divide in internet use and digital device ownership in our sample of South Asian adults. Being female, frequent internet use, being confident in filling out medical forms, and preferring written information in English were all positive independent predictors of using the internet for health information purposes in internet users. Age independently influenced whether participants reported having downloaded a health and fitness app. Those who preferred written information in languages other than English showed less interest in all modes of future eHealth support.

\section{Comparison With Previous Research in the South Asian Community}

At the time the survey was conducted in 2014, our study was unique in that it was the first to use a community-based approach, where we mobilized community resources in health, faith gathering, and other settings to explore ownership of digital devices, internet use, and willingness to use eHealth tools specifically among members of the South Asian community in Canada. Furthermore, to our knowledge, it remains to be the only study to explore the predictors of these outcomes in this growing ethnocultural minority group. Data on the use and uptake of technology to address health needs in South Asians in India [41], Sri Lanka [42], and Pakistan [43] have suggested highly variable rates of web-based health information seeking among internet users (ie, 1\%-75\%). Our findings are comparable with data reported from a 2009-2010 survey of 709 South Asian adults living in the metropolitan Washington DC region, which found that the internet was the leading source of health information (76.9\%) [44]. They also found that older participants and those who were US born were more likely to obtain health information from physicians rather than the internet, whereas those who rarely or never speak English at home are more likely to cite friends as a source of health information rather than the internet. We also found that language preference and age were predictors of web-based health information seeking, whereas the duration of time lived in Canada was not a predictor.

\section{Comparison With Previous Research in the General Population}

Previous research exploring variables influencing internet use has identified age [32,45], education [46-49], English language proficiency [47,50], and health literacy [51] as predictors of internet use. Similarly, we found education to be a strong predictor of internet use, whereas preference for South Asian languages (rather than English) predicted lower odds of internet 
use. We did not find a relationship between internet use and recent immigration [52] or the presence of chronic conditions [53]. An analysis of the 2010 Canadian internet use survey documented that recent immigrants to Canada have lower rates of internet access but that recent immigrants who are on the web have significantly higher levels of web-based activity than Canadian-born residents and earlier immigrants [52]. Although recent studies do not suggest differential internet uptake between males and females [46], in our sample, we found that being female was independently associated with a lower likelihood of internet use. Although gender inequality has existed in South Asian culture [54,55] and may contribute to this difference, males and females in our study gave similar reasons for not being internet users.

Although several theories have been used to explain health information seeking on the internet, the most recent reviews of methods and measures for health information do not provide insight into the factors predicting the uptake of these behaviors [56,57]. Most studies investigating predictors of using the internet for health information purposes identify age, female sex, and educational attainment as independent sociodemographic predictors, whereas other studies have also identified other demographic factors (race, income, and employment), health status, health care access, and digital literacy factors (eg, internet usage intensity) as mediators of web-based health information seeking [57-64]. Although inconsistent, most studies have found that age is a significant predictor of web-based health information-seeking behaviors $[58,59,61]$. Generally, as age increases, web-based health information seeking decreases; however, the relationship is complex. For example, Veenhof et al [48] documented that Canadians aged 16 to 25 years were significantly less likely to go on the web to search for health-related information than Canadians aged 26 to 65 years. Interestingly, among all respondents in our study, increasing age was a negative predictor of web-based information seeking; however, it was not a significant predictor among internet users. Our finding that female internet users are more likely to be web-based health information seekers is consistent with that reported by others [58-60,62].

Similar to others, we found that smartphone or tablet owners were more likely to be younger, affluent, and highly educated than nonowners [31]. Our finding that $30 \%$ of smartphone or tablet owners used health apps is consistent with the range of $19 \%$ to $58 \%$ reported in studies of racially diverse Americans $[36,65,66]$. Our finding that younger individuals were more likely to use health apps is consistent with a national survey of 1604 American mobile phone users that found individuals who were younger, had higher income, were more educated, were Latino or Hispanic, and had a BMI in the obese range were more likely to use health apps [66].

Finally, several studies have explored willingness to get on the web and future use of eHealth tools [67-73]. Our finding that $32 \%$ of noninternet users thought they would go on the web is higher than the $8 \%$ who said they would like to start using the internet or email in a recent Pew Research Centre survey [67]. Encouragingly, $67 \%$ of noninternet users reported that they would likely go on the web in the future, indicating that they would be willing to take a workshop or learn from a friend or family member (72\%). Other surveys have reported varying levels of interest in specific eHealth interventions, from highs of $83 \%$ of women willing to participate in an internet-based postpartum weight loss intervention [68] to lows where only $18 \%$ preferred to learn health, wellness, and lifestyle information from a mobile app [70]. Recently, a qualitative study of British South Asians suggested that short text messages to support medication adherence for type 2 diabetes would be acceptable and relevant [74]. Although limited research exists, language preferences and age have been found to predict willingness to use internet or smartphone app-based interventions for health $[71,73]$, consistent with our finding that increasing age is a negative predictor of app use.

\section{Clinical Implications}

First, our results suggest that community-based, culturally tailored strategies would be welcomed and are required to reduce identified digital divides and increase the uptake and use of credible web-based and app-based resources for health purposes among South Asian adults who are current internet users and nonusers. This is particularly timely, given the need to consider and increase remote delivery of health care based on social distancing as a result of the COVID-19 pandemic. Although eHealth and mHealth interventions appear to be more likely to reach certain subgroups of individuals, such as those that are younger, English speaking, and with high educational achievement, particular attention must be paid not to exacerbate health inequities based on these digital divides. Although most internet users were interested in YouTube or web-based peer support interventions, a range of eHealth interventions will be needed to meet the needs of various subgroups within the community. Device and internet training offered in a culturally relevant way for noninternet users who are interested in getting on the web may reduce identified divides, whereas different means, such as using friends or family as intermediaries, will be required to reach noninternet users, particularly those who have no intention to get on the web. Second, as web-based resources are not designed to replace health professional interactions [75], health care professionals and health organizations must play an important role in referring and supporting patients to access credible eHealth resources, including those that are tailored specifically to South Asian health needs.

\section{Limitations}

Our study has several limitations. First, as nonprobability (ie, convenience) sampling was used, selection bias and sampling error make generalizability to the larger South Asian population a concern. We did not translate our survey into other commonly spoken languages (eg, Hindi, Urdu), and our results primarily pertain to the English- and Punjabi-speaking Sikh community. Second, our data were collected in 2014 and are likely not reflective of evolution in the use or ownership patterns. Third, the survey tool itself is not validated; however, most questions were sourced from existing large national surveys or other validated surveys. We recognize that the question relating to language preference for written health information could have been improved by instead asking about the primary language 
spoken in the home and that the use of a single health literacy screening question, rather than a full health literacy questionnaire, is not optimal. Although smoking is a well-established risk factor for CVD [76], we did not ask about smoking status or use of web-based health information or apps for smoking cessation as part of our survey. This was based on evidence that South Asian Canadians are less likely to be current or former smokers than Canadians of European descent [77] and that smoking is very rare among South Asian Canadian women [78]. Interestingly, a survey conducted around the same time as ours in British Columbia, Canada, also suggested that smoking rates are considerably lower in South Asians than in the general population (never smokers: $87 \%$ vs 59\%) [79], as does other Canadian research [3]. However, our exclusion of smoking status may be an oversight, as surveys may fail to accurately capture the use of culturally specific smokeless tobacco products [80]. Furthermore, although the survey was translated into Punjabi and formally pretested, community volunteers were trained to administer the survey in Punjabi and 2 volunteers administered just more than $50 \%$ of the surveys, there may have been issues with conceptual translation and variability in survey administration. We had some issues with the early version of the survey administered on paper, which resulted in missing data for certain items. Fourth, volunteer and social desirability bias may overinflate our estimates of device ownership, internet use, and willingness to use future eHealth tools. In addition, self-report may have introduced recall bias in outcome and demographic variables. Fifth, the questions relating to likeliness to use eHealth interventions in the future were hypothetical and therefore may overestimate actual willingness had we asked participants to participate in a pilot test of eHealth interventions. Finally, we did not explore differences in survey responses by survey mode or by recruitment location.

\section{Conclusions}

Our survey provides insights into digital divides according to language preferences, education, age, and sex in an ethnocultural minority community in Canada. The high overall rates of internet use for health information, digital device ownership, and interest in eHealth-based interventions in internet users along with high access to individuals who could help them use the internet among nonusers suggest that eHealth supports are feasible among segments of English- or Punjabi-speaking South Asian adults. There is an opportunity for health care providers and health organizations to enhance the use of reliable and culturally relevant eHealth resources to promote health, prevent chronic disease, and support self-management of chronic health conditions for South Asian adults.

\section{Acknowledgments}

This work was generously supported by the Lawson Foundation (grant number GRT 2012-057). They had no role in the design, collection, analysis, or interpretation of data, writing of the report, or decision to submit the paper for publication. The authors wish to acknowledge the members of the South Asian Communities in the Edmonton Area who participated in the e-Patient Project, e-Patient Project Advisory Committee Members, particularly Dr Sudheer Sharma, Mr Jesse Bhondi, Ms Nandini Desai, Mr Jasbir Bhui, and Ms Sanjeet Chattha. The authors thank those who provided access to the participating sites Medicine Shoppe Pharmacy \#170, Meadowbrook Medical Clinic (Dr Narpinder Hans), Gurdwara Millwoods, Gurdwara Singh Sabha, Gurdwara Nanaksar, Sikh Society of Alberta, Hindu Society of Alberta, Bharthia Cultural Society, Millwoods Cultural Society of Retired \& Semi Retired, Mill Woods Seniors Activity Centre, and organizers of community events (Nagar Kirtan and Tiyan Da Mela) where the survey was administered. The authors thank Ms. Kaitlin Laurisden and Dr Bikram Jammu who served as project coordinators and oversaw the coordination of the survey. The authors thank Ms Manjot Bhui, Ms Lakwinder Grewal, the numerous other community volunteers including those from Headway School and J Percy Page School for assisting with survey administration. They thank Mr Kirtmeet Singh Kohar at the Nawi Dunia Newspaper, Ms Nirlep Kaur Rai, and Mr Jagwinder Singh Sidhu for assistance in the survey translation. The authors thank the Health Sciences Research \& Education Commons at the University of Alberta for loaning tablet computers to the research team for survey administration. They thank Dr Ken Cor for facilitating access to the Qualtrics web-based survey platform and helping in survey development. The authors acknowledge the EPICORE Center at the University of Alberta for conducting the multivariable regression analysis. Finally, the authors thank Dr Ravina Sanghera and Dr Lisa Guirguis for their thoughtful comments on this manuscript.

\section{Authors' Contributions}

All authors contributed to conception and design, critical revision of the manuscript for intellectual content, and final approval of the version to be published. MM contributed to acquisition and analysis and interpretation of data and prepared the first draft of the manuscript.

\section{Conflicts of Interest}

None declared.

\section{Multimedia Appendix 1}

e-Patient Project Survey. 


\section{Multimedia Appendix 2}

Web-based health information-seeking patterns and preferences for future eHealth interventions in internet users. [DOCX File, 36 KB-Multimedia Appendix 2]

\section{Multimedia Appendix 3}

Predictors of being an internet user, using the web for health information, smartphone or table ownership, and having health and fitness apps.

[DOCX File, 22 KB-Multimedia Appendix 3]

\section{Multimedia Appendix 4}

Determinants associated with being likely or very likely to use different modes of eHealth support in the future in internet users. [DOCX File, 37 KB-Multimedia Appendix 4]

\section{References}

1. Visible Minority Population and Population Group Reference Guide, 2006 Census. Statistics Canada. 2006. URL: https:/ /www12.statcan.gc.ca/census-recensement/2006/ref/rp-guides/visible minority-minorites visibles-eng.cfm [accessed 2012-05-17]

2. Fernando E, Razak F, Lear SA, Anand SS. Cardiovascular disease in South Asian migrants. Can J Cardiol 2015 Sep;31(9):1139-1150. [doi: 10.1016/j.cjca.2015.06.008] [Medline: 26321436]

3. Rana A, de Souza RJ, Kandasamy S, Lear SA, Anand SS. Cardiovascular risk among South Asians living in Canada: a systematic review and meta-analysis. CMAJ Open 2014 Jul;2(3):E183-E191 [FREE Full text] [doi: 10.9778/cmajo.20130064] [Medline: 25295238]

4. Zaman MJ, Philipson P, Chen R, Farag A, Shipley M, Marmot MG, et al. South Asians and coronary disease: is there discordance between effects on incidence and prognosis? Heart 2013 May;99(10):729-736 [FREE Full text] [doi: 10.1136/heartjnl-2012-302925] [Medline: 23406688]

5. Yusuf S, Hawken S, Ounpuu S, Dans T, Avezum A, Lanas F, INTERHEART Study Investigators. Effect of potentially modifiable risk factors associated with myocardial infarction in 52 countries (the INTERHEART study): case-control study. Lancet 2004;364(9438):937-952. [doi: 10.1016/S0140-6736(04)17018-9] [Medline: 15364185]

6. Volgman AS, Palaniappan LS, Aggarwal NT, Gupta M, Khandelwal A, Krishnan AV, American Heart Association Council on EpidemiologyPrevention; Cardiovascular DiseaseStroke in WomenSpecial Populations Committee of the Council on Clinical Cardiology; Council on CardiovascularStroke Nursing; Council on Quality of CareOutcomes Research;Stroke Council. Atherosclerotic cardiovascular disease in South Asians in the United States: epidemiology, risk factors, and treatments: a scientific statement from the American heart association. Circulation 2018 Jul 3;138(1):e1-e34. [doi: 10.1161/CIR.0000000000000580] [Medline: 29794080]

7. Bhurji N, Javer J, Gasevic D, Khan NA. Improving management of type 2 diabetes in South Asian patients: a systematic review of intervention studies. BMJ Open 2016 Apr 20;6(4):e008986 [FREE Full text] [doi: 10.1136/bmjopen-2015-008986] [Medline: 27098819]

8. Khan NA, Wang H, Anand S, Jin Y, Campbell NR, Pilote L, et al. Ethnicity and sex affect diabetes incidence and outcomes. Diabetes Care 2011 Jan 1;34(1):96-101 [FREE Full text] [doi: 10.2337/dc10-0865] [Medline: 20978094]

9. Mohan V, Mathur P, Deepa R, Deepa M, Shukla DK, Menon GR, et al. Urban rural differences in prevalence of self-reported diabetes in India--the WHO-ICMR Indian NCD risk factor surveillance. Diabetes Res Clin Pract 2008 Apr;80(1):159-168. [doi: 10.1016/j.diabres.2007.11.018] [Medline: 18237817]

10. Creatore MI, Moineddin R, Booth G, Manuel DH, DesMeules M, McDermott S, et al. Age- and sex-related prevalence of diabetes mellitus among immigrants to Ontario, Canada. Can Med Assoc J 2010 May 18;182(8):781-789 [FREE Full text] [doi: 10.1503/cmaj.091551] [Medline: 20403889]

11. Gujral UP, Pradeepa R, Weber MB, Narayan KM, Mohan V. Type 2 diabetes in South Asians: similarities and differences with white caucasian and other populations. Ann N Y Acad Sci 2013 Apr;1281:51-63 [FREE Full text] [doi: 10.1111/j.1749-6632.2012.06838.x] [Medline: 23317344]

12. Sattar N, Gill JM. Type 2 diabetes in migrant south Asians: mechanisms, mitigation, and management. Lancet Diabetes Endocrinol 2015 Dec;3(12):1004-1016. [doi: 10.1016/S2213-8587(15)00326-5] [Medline: 26489808]

13. Eckel RH, Jakicic JM, Ard JD, de Jesus JM, Houston MN, Hubbard VS, American College of Cardiology/American Heart Association Task Force on Practice Guidelines. 2013 AHA/ACC guideline on lifestyle management to reduce cardiovascular risk: a report of the American college of cardiology/American heart association task force on practice guidelines. J Am Coll Cardiol 2014 Jul 1;63(25 Pt B):2960-2984 [FREE Full text] [doi: 10.1016/j.jacc.2013.11.003] [Medline: 24239922]

14. Diabetes Canada Clinical Practice Guidelines Expert Committee, Prebtani AP, Bajaj HS, Goldenberg R, Mullan Y. Reducing the risk of developing diabetes. Can J Diabetes 2018 Apr;42(Suppl 1):S20-S26. [doi: 10.1016/j.jcjd.2017.10.033] [Medline: 29650097] 
15. Shah BR, Cauch-Dudek K, Anand SS, Austin PC, Manuel DG, Hux JE. Absence of disparities in the quality of primary diabetes care for South Asians and Chinese in an urban Canadian setting. Diabetes Care 2012 Apr;35(4):794-796 [FREE Full text] [doi: 10.2337/dc11-1845] [Medline: 22323411]

16. Misra A, Ramchandran A, Jayawardena R, Shrivastava U, Snehalatha C. Diabetes in South Asians. Diabet Med 2014 Oct;31(10):1153-1162. [doi: 10.1111/dme.12540] [Medline: 24975549]

17. Sohal T, Sohal P, King-Shier KM, Khan NA. Barriers and facilitators for type-2 diabetes management in South Asians: a systematic review. PLoS One 2015;10(9):e0136202 [FREE Full text] [doi: 10.1371/journal.pone.0136202] [Medline: 26383535]

18. Shariff AI, Kumar N, Yancy WS, Corsino L. Type 2 diabetes and atherosclerotic cardiovascular disease in South Asians: a unique population with a growing challenge. Curr Diab Rep 2020 Jan 30;20(1):4. [doi: 10.1007/s11892-020-1291-6] [Medline: 32002674]

19. Meier CA, Fitzgerald MC, Smith JM. eHealth: extending, enhancing, and evolving health care. Annu Rev Biomed Eng 2013;15:359-382. [doi: 10.1146/annurev-bioeng-071812-152350] [Medline: 23683088]

20. Oldenburg B, Taylor CB, O'Neil A, Cocker F, Cameron LD. Using new technologies to improve the prevention and management of chronic conditions in populations. Annu Rev Public Health 2015 Mar 18;36:483-505. [doi: 10.1146/annurev-publhealth-031914-122848] [Medline: 25581147]

21. Devi R, Singh SJ, Powell J, Fulton EA, Igbinedion E, Rees K. Internet-based interventions for the secondary prevention of coronary heart disease. Cochrane Database Syst Rev 2015(12):CD009386. [doi: 10.1002/14651858.CD009386.pub2] [Medline: 26691216]

22. Beishuizen CR, Stephan BC, van Gool WA, Brayne C, Peters RJ, Andrieu S, et al. Web-based interventions targeting cardiovascular risk factors in middle-aged and older people: a systematic review and meta-analysis. J Med Internet Res 2016 Mar 11;18(3):e55 [FREE Full text] [doi: 10.2196/jmir.5218] [Medline: 26968879]

23. Pal K, Eastwood SV, Michie S, Farmer AJ, Barnard ML, Peacock R, et al. Computer-based diabetes self-management interventions for adults with type 2 diabetes mellitus. Cochrane Database Syst Rev 2013 Mar 28(3):CD008776 [FREE Full text] [doi: 10.1002/14651858.CD008776.pub2] [Medline: 23543567]

24. Cotter AP, Durant N, Agne AA, Cherrington AL. Internet interventions to support lifestyle modification for diabetes management: a systematic review of the evidence. J Diabetes Complications 2014;28(2):243-251 [FREE Full text] [doi: 10.1016/j.jdiacomp.2013.07.003] [Medline: 24332469]

25. Tao D, Wang T, Wang T, Liu S, Qu X. Effects of consumer-oriented health information technologies in diabetes management over time: a systematic review and meta-analysis of randomized controlled trials. J Am Med Inform Assoc 2017 Sep 1;24(5):1014-1023. [doi: 10.1093/jamia/ocx014] [Medline: 28340030]

26. Davachi S, Flynn M, Al E. A health region/community partnership for type 2 diabetes risk factor screening in Indo-Asian communities. Can Med Assoc J 2005;29(2):87-94.

27. van Draanen J, Shafique A, Farissi A, Wickramanayake D, Kuttaiya S, Oza S, et al. How to offer culturally relevant type 2 diabetes screening: lessons learned from the South Asian diabetes prevention program. Can J Diabetes 2014 Oct;38(5):329-333. [doi: 10.1016/j.jcjd.2013.11.008] [Medline: 24797496]

28. University of British Columbia. iCON: InterCultural Online Health Network. iCON. URL: http://iconproject.org [accessed 2017-07-17]

29. STOP Diabetes Foundation. Stop Diabetes Foundation. URL: http://www.stopdiabetesfoundation.com/index.html [accessed 2017-07-20]

30. DIL Walk. DIL Walk Foundation. URL: http://www.dilwalk.ca [accessed 2017-07-20]

31. Anderson M. Technology Device Ownership. Pew Research Centre. 2015 Oct. URL: http://www.pewinternet.org/2015/10/ 29/device-ownership-2015-about-this-report/ [accessed 2016-08-11]

32. Individual Internet use and E-commerce. Statistics Canada. 2013 Apr 15. URL: http://www.statcan.gc.ca/daily-quotidien/ 111012/dq111012a-eng.htm [accessed 2012-05-21]

33. Canadian Internet Use Survey, 2012. Statistics Canada. 2012. URL: http://www.statcan.gc.ca/daily-quotidien/131126/ dq131126d-eng.pdf [accessed 2012-05-21]

34. Fox S, Duggan M. Health Online 2013. Pew Research Center Internet \& Technology. 2013. URL: http://www.pewinternet.org/ 2013/01/15/health-online-2013/ [accessed 2016-08-13]

35. Yoon H, Jang Y, Vaughan PW, Garcia M. Older adults' internet use for health information: digital divide by race/ethnicity and socioeconomic status. J Appl Gerontol 2020 Jan;39(1):105-110. [doi: 10.1177/0733464818770772] [Medline: 29661052]

36. Fox S, Duggan M. Mobile Health 2012. Pew Research Center Internet \& Technology. 2012. URL: http://www. pewinternet.org/2012/11/08/mobile-health-2012/ [accessed 2016-08-20]

37. Fox S, Duggan M. Tracking for Health. Pew Research Center Internet \& Technology. 2013. URL: http://www.pewinternet.org/ 2013/01/28/tracking-for-health/ [accessed 2016-08-23]

38. Norman CD, Skinner HA. eHEALS: the eHealth literacy scale. J Med Internet Res 2006 Nov;8(4):e27 [FREE Full text] [doi: 10.2196/jmir.8.4.e27] [Medline: 17213046]

39. Chew LD, Bradley KA, Boyko EJ. Brief questions to identify patients with inadequate health literacy. Fam Med 2004 Sep;36(8):588-594 [FREE Full text] [Medline: 15343421] 
40. Process of Translation and Adaptation of Instruments. World Health Organization. URL: http://www.who.int/substance_abuse/ research tools/translation/en/ [accessed 2014-04-07]

41. Akerkar SM, Kanitkar M, Bichile LS. Use of the Internet as a resource of health information by patients: a clinic-based study in the Indian population. J Postgrad Med 2005;51(2):116-118 [FREE Full text] [Medline: 16006703]

42. Kommalage M. Use of the internet by patients attending specialist clinics in Sri Lanka: a cross sectional study. BMC Med Inform Decis Mak 2009 Feb 12;9:12 [FREE Full text] [doi: 10.1186/1472-6947-9-12] [Medline: 19210796]

43. Shaikh IA, Shaikh MA, Kamal A, Masood S. Internet access and utilization for health information among university students in Islamabad. J Ayub Med Coll Abbottabad 2008;20(4):153-156. [Medline: 19999231]

44. Vyas AN, Chaudhary N, Ramiah K, Landry M. Addressing a growing community's health needs: Project SAHNA (South Asian health needs assessment). J Immigr Minor Health 2013 Jun;15(3):577-583. [doi: 10.1007/s10903-012-9655-X] [Medline: 22684910]

45. Smith A. Older Adults and Technology Use. Pew Research Center. 2014. URL: http://www.pewinternet.org/2014/04/03/ older-adults-and-technology-use/ [accessed 2016-08-11]

46. Perrin A, Duggan M. Americans' Internet Access: 2000-2015. Pew Research Center. 2015. URL: http://www.pewinternet.org/ 2015/06/26/americans-internet-access-2000-2015/ [accessed 2016-08-10]

47. Knapp C, Madden V, Wang H, Sloyer P, Shenkman E. Internet use and eHealth literacy of low-income parents whose children have special health care needs. J Med Internet Res 2011;13(3):e75 [FREE Full text] [doi: 10.2196/jmir.1697] [Medline: 21960017]

48. Veenhof B, Clermont Y, Sciadas G. Literacy and Digital Technologies: Linkages and Outcomes. Statistics Canada. URL: http://www.statcan.gc.ca/pub/56f0004m/56f0004m2005012-eng.htm [accessed 2016-08-19]

49. Chou WS, Liu B, Post S, Hesse B. Health-related Internet use among cancer survivors: data from the health Information national trends survey, 2003-2008. J Cancer Surviv 2011 Sep;5(3):263-270. [doi: 10.1007/s11764-011-0179-5] [Medline: 21505861]

50. Zickuhr KS. Digital differences. Pew Research Center. 2012. URL: http://www.pewinternet.org/2012/04/13/ digital-differences/ [accessed 2016-08-23]

51. Bailey SC, O'Conor R, Bojarski EA, Mullen R, Patzer RE, Vicencio D, et al. Literacy disparities in patient access and health-related use of Internet and mobile technologies. Health Expect 2015 Dec;18(6):3079-3087 [FREE Full text] [doi: 10.1111/hex.12294] [Medline: 25363660]

52. Haight M, Quan-Haase A, Corbett BA. Revisiting the digital divide in Canada: the impact of demographic factors on access to the internet, level of online activity, and social networking site usage. Inf Commun Soc 2014 Mar 7;17(4):503-519. [doi: 10.1080/1369118x.2014.891633]

53. The Diagnosis Difference. Pew Research Center Science \& Society. 2013. URL: http://www.pewinternet.org/2013/11/26/ the-diagnosis-difference/ [accessed 2016-08-15]

54. Bajaj S, Jawad F, Islam N, Mahtab H, Bhattarai J, Shrestha D, et al. South Asian women with diabetes: psychosocial challenges and management: Consensus statement. Indian J Endocrinol Metab 2013 Jul;17(4):548-562 [FREE Full text] [doi: 10.4103/2230-8210.113720] [Medline: 23961469]

55. Assanand S, Dias M, Richardson E, Chambers N, Waxler-Morrison N. People of South Asian descent. In: Cross-Cultural Caring, 2nd ed. Vancouver, BC: UBC Press; 2005:197-246.

56. Anker AE, Reinhart AM, Feeley TH. Health information seeking: a review of measures and methods. Patient Educ Couns 2011 Mar;82(3):346-354. [doi: 10.1016/j.pec.2010.12.008] [Medline: 21239134]

57. Marton C, Choo CW. A review of theoretical models of health information seeking on the web. J Doc 2012 Apr 20;68(3):330-352. [doi: 10.1108/00220411211225575]

58. Li J, Theng Y, Foo S. Predictors of online health information seeking behavior: changes between 2002 and 2012. Health Informatics J 2016 Dec;22(4):804-814 [FREE Full text] [doi: 10.1177/1460458215595851] [Medline: 26261218]

59. Rice RE. Influences, usage, and outcomes of Internet health information searching: multivariate results from the pew surveys. Int J Med Inform 2006 Jan;75(1):8-28. [doi: 10.1016/j.ijmedinf.2005.07.032] [Medline: 16125453]

60. Baker L, Wagner TH, Singer S, Bundorf MK. Use of the Internet and e-mail for health care information: results from a national survey. J Am Med Assoc 2003 May 14;289(18):2400-2406. [doi: 10.1001/jama.289.18.2400] [Medline: 12746364]

61. Andreassen HK, Bujnowska-Fedak MM, Chronaki CE, Dumitru RC, Pudule I, Santana S, et al. European citizens' use of E-health services: a study of seven countries. BMC Public Health 2007 Apr 10;7:53 [FREE Full text] [doi: $\underline{10.1186 / 1471-2458-7-53}$ ] [Medline: $\underline{17425798]}$

62. Kontos E, Blake KD, Chou WS, Prestin A. Predictors of eHealth usage: insights on the digital divide from the health information national trends survey 2012. J Med Internet Res 2014 Jul 16;16(7):e172 [FREE Full text] [doi: 10.2196/jmir.3117] [Medline: 25048379]

63. Amante DJ, Hogan TP, Pagoto SL, English TM, Lapane KL. Access to care and use of the Internet to search for health information: results from the US national health interview survey. J Med Internet Res 2015 Apr 29;17(4):e106 [FREE Full text] [doi: 10.2196/jmir.4126] [Medline: 25925943]

64. Renahy E, Chauvin P. Internet uses for health information seeking. Revue d'Épidémiologie et de Santé Publique 2006 Jun 21;54(3):263-275. [doi: 10.1016/s0398-7620(06)76721-9] 
65. Bender MS, Choi J, Arai S, Paul SM, Gonzalez P, Fukuoka Y. Digital technology ownership, usage, and factors predicting downloading health apps among caucasian, filipino, korean, and latino americans: the digital link to health survey. JMIR Mhealth Uhealth 2014 Oct 22;2(4):e43 [FREE Full text] [doi: 10.2196/mhealth.3710] [Medline: 25339246]

66. Krebs P, Duncan DT. Health app use among US mobile phone owners: a national survey. JMIR Mhealth Uhealth 2015 Nov 4;3(4):e101 [FREE Full text] [doi: 10.2196/mhealth.4924] [Medline: 26537656]

67. Zickuhr K. Who's Not Online and Why? Pew Research Center. 2013. URL: http://www.pewinternet.org/2013/09/25/ whos-not-online-and-why/ [accessed 2016-08-16]

68. Urrutia RP, Berger AA, Ivins AA, Beckham AJ, Thorp JM, Nicholson WK. Internet use and access among pregnant women via computer and mobile phone: implications for delivery of perinatal care. JMIR Mhealth Uhealth 2015 Mar 30;3(1):e25 [FREE Full text] [doi: 10.2196/mhealth.3347] [Medline: 25835744]

69. Sarkar U, Piette JD, Gonzales R, Lessler D, Chew LD, Reilly B, et al. Preferences for self-management support: findings from a survey of diabetes patients in safety-net health systems. Patient Educ Couns 2008 Jan;70(1):102-110 [FREE Full text] [doi: 10.1016/j.pec.2007.09.008] [Medline: 17997264]

70. Comstock J. Survey: Only 30 Percent of Insured Consumers Want to Track Health on a Mobile Device. MobiHealthNews. 2015 Jun 8. URL: http://mobihealthnews.com/44159/ survey-only-30-percent-of-insured-consumers-want-to-track-health-on-a-mobile-device [accessed 2016-08-22]

71. Alley S, Schoeppe S, Guertler D, Jennings C, Duncan MJ, Vandelanotte C. Interest and preferences for using advanced physical activity tracking devices: results of a national cross-sectional survey. BMJ Open 2016 Jul 7;6(7):e011243 [REE Full text] [doi: 10.1136/bmjopen-2016-011243] [Medline: 27388359]

72. Hughes LD, Done J, Young A. Not 2 old 2 TXT: there is potential to use email and SMS text message healthcare reminders for rheumatology patients up to 65 years old. Health Informatics J 2011 Dec;17(4):266-276 [FREE Full text] [doi: 10.1177/1460458211422019] [Medline: 22193827]

73. James DC, Harville C. Smartphone usage, social media engagement, and willingness to participate in mHealth weight management research among African American Women. Health Educ Behav 2018 Jun;45(3):315-322. [doi: 10.1177/1090198117714020] [Medline: 28606004]

74. Prinjha S, Ricci-Cabello I, Newhouse N, Farmer A. British South Asian patients' perspectives on the relevance and acceptability of mobile health text messaging to support medication adherence for type 2 diabetes: qualitative study. JMIR Mhealth Uhealth 2020 Apr 20;8(4):e15789 [FREE Full text] [doi: 10.2196/15789] [Medline: 32310150]

75. McMullan M. Patients using the Internet to obtain health information: how this affects the patient-health professional relationship. Patient Educ Couns 2006 Oct;63(1-2):24-28. [doi: 10.1016/j.pec.2005.10.006] [Medline: 16406474]

76. Ezzati M, Henley SJ, Thun MJ, Lopez AD. Role of smoking in global and regional cardiovascular mortality. Circulation 2005 Jul 26;112(4):489-497. [doi: 10.1161/CIRCULATIONAHA.104.521708] [Medline: 16027251]

77. Anand SS, Yusuf S, Vuksan V, Devanesen S, Teo KK, Montague PA, et al. Differences in risk factors, atherosclerosis, and cardiovascular disease between ethnic groups in Canada: the study of health assessment and risk in ethnic groups (SHARE). Lancet 2000 Jul 22;356(9226):279-284. [doi: 10.1016/s0140-6736(00)02502-2] [Medline: 11071182]

78. Jones CA, Nanji A, Mawani S, Davachi S, Ross L, Vollman A, et al. Feasibility of community-based screening for cardiovascular disease risk in an ethnic community: the South Asian cardiovascular health assessment and management program (SA-CHAMP). BMC Public Health 2013 Feb 21;13:160 [FREE Full text] [doi: 10.1186/1471-2458-13-160] [Medline: 23432996]

79. South Asian Health Report. Fraser Health Authority. 2015. URL: https://www.fraserhealth.ca/health-topics-a-to-z/ south-asian-health/south-asian-health-institute\#.XwixAy0ZNTY [accessed 2020-07-10]

80. Mukherjea A, Modayil MV. Culturally specific tobacco use and South Asians in the United States: a review of the literature and promising strategies for intervention. Health Promot Pract 2013 Sep;14(5 Suppl):48S-60S. [doi: 10.1177/1524839913485585] [Medline: 23690257]

\section{Abbreviations}

AUC: area under the curve

CVD: cardiovascular disease

mHealth: mobile health

OR: odds ratio

VIF: variance inflation factor 
Edited by G Eysenbach; submitted 25.05.20; peer-reviewed by B Sainz-de-Abajo, A Budenz; comments to author 15.06.20; revised version received 20.07.20; accepted 29.10.20; published 08.01.21

Please cite as:

Makowsky MJ, Jones CA, Davachi S

Prevalence and Predictors of Health-Related Internet and Digital Device Use in a Sample of South Asian Adults in Edmonton, Alberta, Canada: Results From a 2014 Community-Based Survey

JMIR Public Health Surveill 2021;7(1):e20671

URL: https://publichealth.jmir.org/2021/1/e20671

doi: $\underline{10.2196 / 20671}$

PMID: $\underline{3416506}$

CMark J Makowsky, Charlotte A Jones, Shahnaz Davachi. Originally published in JMIR Public Health and Surveillance (http://publichealth.jmir.org), 08.01.2021. This is an open-access article distributed under the terms of the Creative Commons Attribution License (https://creativecommons.org/licenses/by/4.0/), which permits unrestricted use, distribution, and reproduction in any medium, provided the original work, first published in JMIR Public Health and Surveillance, is properly cited. The complete bibliographic information, a link to the original publication on http://publichealth.jmir.org, as well as this copyright and license information must be included. 